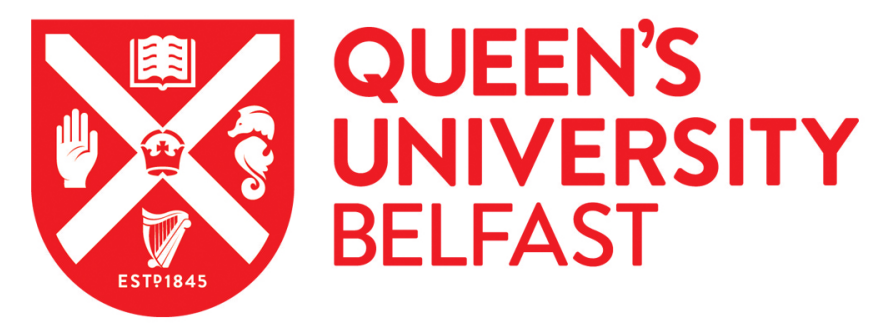

\title{
Adolescent men's attitudes and decision making in relation to pregnancy and pregnancy outcomes: An integrative review of the literature from 2010 to 2017
}

Kane, J., Lohan, M., \& Kelly, C. (2019). Adolescent men's attitudes and decision making in relation to pregnancy and pregnancy outcomes: An integrative review of the literature from 2010 to 2017. Journal of Adolescence, 72, 23-31. https://doi.org/10.1016/j.adolescence.2018.12.008

Published in:

Journal of Adolescence

Document Version:

Peer reviewed version

Queen's University Belfast - Research Portal:

Link to publication record in Queen's University Belfast Research Portal

\begin{abstract}
Publisher rights
Copyright 2019 Elsevier.

This manuscript is distributed under a Creative Commons Attribution-NonCommercial-NoDerivs License

(https://creativecommons.org/licenses/by-nc-nd/4.0/), which permits distribution and reproduction for non-commercial purposes, provided the author and source are cited

\section{General rights}

Copyright for the publications made accessible via the Queen's University Belfast Research Portal is retained by the author(s) and / or other copyright owners and it is a condition of accessing these publications that users recognise and abide by the legal requirements associated with these rights.
\end{abstract}

\section{Take down policy}

The Research Portal is Queen's institutional repository that provides access to Queen's research output. Every effort has been made to ensure that content in the Research Portal does not infringe any person's rights, or applicable UK laws. If you discover content in the Research Portal that you believe breaches copyright or violates any law, please contact openaccess@qub.ac.uk. 
Adolescent Men's Attitudes and Decision Making in Relation to Pregnancy and Pregnancy Outcomes: An Integrative Review of the Literature From 2010 - 2017

Joleen Kane, Prof Maria Lohan (Corresponding Author) and Dr Carmel Kelly

\section{Contact Details}

Joleen Kane, Queen's University Belfast, School of Nursing and Midwifery, 97 Lisburn Rd, Belfast BT9 7BL, jkane27@qub.ac.uk

Maria Lohan, Queen's University Belfast, School of Nursing and Midwifery, 97 Lisburn Rd, Belfast BT9 7BL, mlohan@qub.ac.uk, +44 (0)28 90972839

Carmel Kelly, Queen's University Belfast, School of Nursing and Midwifery, 97 Lisburn Rd, Belfast, BT9 7BL, carmel.kelly@qub.ac.uk

Declaration of Interest: None

This research did not receive any specific grant from funding agencies in the public, commercial, or not-for-profit sectors. 
Adolescent Men's Attitudes and Decision Making in Relation to Pregnancy and Pregnancy Outcomes: An Integrative Review of the Literature From 2010 - 2017

\begin{abstract}
The review updates a previous review conducted in 2010 (Lohan et al.), summarizing the available literature on young men's attitudes and decision-making in the context of addressing two questions: (1) What are adolescent men's attitudes to adolescent pregnancy? (2) What are adolescent men's attitudes and decision-making in relation to pregnancy outcomes? Using Whittemore and Knafl's process for conducting an integrative review, 38 studies published between 2010 and 2018 reporting on young men's attitudes and decision-making in relation to pregnancy and pregnancy outcomes were analysed. This review exposes gaps in the academic literature, concerning young men's experiences of unintended pregnancy and pregnancy decision making. This review argues that a greater understanding of young men's experiences when they too experience an unintended pregnancy with a partner within a relationship or beyond it is a fundamental first step in offering reproduction and sexual health counselling and services to men. As it stands, we do not yet have a significant body of literature to inform practice development.
\end{abstract}

\title{
Keywords
}

Adolescent pregnancy, Pregnancy Decision-Making, Pregnancy Outcomes, Abortion, Pregnancy Continuation, Attitudes to Pregnancy 


\section{Adolescent Men's Attitudes and Decision Making in Relation to Pregnancy and Pregnancy Outcomes: An Integrative Review of the Literature From 2010 - 2017}

\section{Introduction}

Worldwide Government strategies to reduce adolescent pregnancy have been largely gender neutral or targeted at young women (United Nations (UN), 2006; World Health Organisation (WHO) 2011; WHO, 2020). Within this global policy initiative to reduce unintended pregnancies, however, organisations such as the WHO and the UN recognise that adolescent men's involvement in decisions in relation to preventing and dealing with unintended pregnancies should be considered in clinical practice, health promotion and sexual health education. Today, there is a considerable breadth of research on men and boys - particularly on health, sexuality and masculinities which establishes that their meaningful participation in gender equality produces positive changes in their attitudes, perceptions and behaviours (UN, 2016). This review seeks to explore if this considerable breadth of research on men and boys includes their attitudes and decision making in relation to pregnancy and pregnancy outcomes.

A previous review conducted in 2010 (Lohan et al, 2010) found a small amount of research had been conducted on adolescent men's attitudes to adolescent pregnancy and pregnancy outcome decisions. Findings from this review suggested that adolescent men mostly want to avoid an unintended adolescent pregnancy and that pregnancy resolution choices presented difficult moral choices and that there was a dilemma for adolescent men between wanting to have a say in such choices and wanting to be supportive of a woman's right to choose.

This previous review highlighted a number of gaps in the current research. Firstly, that research on attitudes to pregnancy resolution options tended to over represent the perspectives of university students, as well as men living in socially deprived 
neighbourhoods. Secondly, there is very little research on men's actual experiences of an unintended adolescent pregnancy, as opposed to research based upon a vignette methodology. Thirdly, there are very little international comparative research studies. Such internationally comparative studies could inform how structural constraints on decision-making, such as the availability of abortion services and cultural norms around reproduction in society, affect how adolescents view adolescent pregnancy and make pregnancy-outcome decisions. Lastly, this previous review suggested that future research needs to develop creative recruitment strategies which go beyond recruiting adolescent men through their female partners and clinical settings as current research has tended to over-represent the perspectives of those most engaged in their relationships and/or who are willing to come forward to health services.

This review seeks to inquire if the field of research on adolescent men and unintended pregnancy has developed since the previous review, taking into account research conducted in low-income countries which the previous review excluded.

This review will address two questions:

1. What are adolescent men's attitudes to an adolescent pregnancy?

2. What are adolescent men's attitudes and decision making in relation to pregnancy outcomes?

\section{Methods}

Whittemore and Knafl's (2005) updated integrative review (IR) framework will guide this review. The IR is a broad type of research review method that allows for inclusion of empirical studies with diverse methodologies. The five-stage integrative review of the concept of integration proposed by Whittemore (2005) was used: (a) problem identification; 
(b) literature search; (c) data extraction and evaluation; (d) data analysis; and (d) presentation of the results.

\section{Inclusion and exclusion criteria}

The primary inclusion criteria were as follows:

- $\quad$ Peer reviewed journal articles pertaining to adolescent men where the mean age is between 10 and 24 years in relation to pregnancy and pregnancy outcomes. This age range represents the outer boundaries used in research on adolescents and pregnancy.

- $\quad$ Papers written in the English language.

- $\quad$ Empirical (both quantitative and qualitative) research.

The primary exclusion criteria were as follows:

- $\quad \mathrm{PhD}$ and Masters Theses — first because of the difficulties of access, and second because of the absence of peer review.

- Literature that pertained primarily to adolescent sexual behaviour or activity and/or contraception, or fatherhood, but not in relation to unintended pregnancy or abortion. Additionally, any papers that were focused on the effectiveness of interventions or pregnancy prevention programmes were not included in this literature review, as this was regarded as a separate question.

- Literature primarily related to adults that did not include a sub-analysis of an adolescent population.

- Involuntary pregnancy outcomes such as still birth and miscarriage as the experience of involuntary pregnancy loss is different to unintended pregnancy resolution decision making. 


\section{Search Methods}

Three different methods were used to search for the appropriate literature; database searching, hand searching of key journals and citation searching. Five electronic databases were systematically searched using keywords and MeSH terms, where possible (Appendix 2). These databases were; CINAHL, PsychInfo, Medline, Web of Science and Embase. The databases were searched between 2009 and October 2017 as the previous review (Lohan et al, 2010) was dated up to 2009.

\section{Search Outcome}

A five-stage screening process was undertaken: removal of duplicates, screening of title, abstract review, full paper review and reference tracking on the final selected papers. From the original 804 papers, 38 papers were included in this review (Appendix 1). Results from all database searches were exported into RefWorks.

\section{Data Abstraction}

All duplicate records were removed and two researchers (JK and ML) title screened the remaining 804 papers. One researcher $(\mathrm{JK})$ undertook review at the abstract and full paper stage, with a second researcher (ML) reviewing $25 \%$ of the included papers. Reference lists of all included papers were also reviewed.

\section{Quality Appraisal}

The Mixed Methods Assessment Tool (MMAT) was used to critically appraise the quality of the included studies because it has moderate to excellent reliability (Pluye et al., 2011) and can be used to assess multiple study designs. The final papers were reviewed by JK with ML conducting an independent review of $25 \%$ of the final papers. Using the MMAT classification, 29 studies scored 100\%, seven studies scored $75 \%$ and two studies scored 
$50 \%$. The limitations section on the table of included studies (Appendix 3) highlights any weaknesses in design that were identified during this process.

\section{Data Analysis and Synthesis}

Articles were recorded on data collection sheets that consisted of the following subheadings: author and title, study design, participants, relevant results and limitations (See Appendix 3). The results from quantitative, qualitative and mixed-method studies were described, compared item by item, and explored for similarities, differences and relationships between data (Whittemore \& Knafl, 2005).

A narrative synthesis approach was used to synthesize both qualitative and quantitative evidence. This process involved the conversion of all data into narrative through qualitative analysis (Mays, Pope, \& Popay, 2005). The quantitative findings were translated into narrative statements, and then closely apposed to the qualitative evidence in order to enable a deeper understanding of, and a critical reflection upon the quantitative findings (Pearson et al., 2014). Similar findings were then categorized and grouped through an iterative process of reading and re-reading of the studies retrieved. Themes related to young men's attitudes to unintended pregnancy and pregnancy resolution decision making were identified (Whittemore \& Knafl, 2005).

\section{Results}

From an identified 804 papers, 38 papers were included in this review (Appendix 3). A range of methodological designs were included: qualitative $(n=19)$; quantitative $(n=15)$ and mixed methods $(n=4)$. Most studies were conducted in the US $(n=19)$ and Africa $(n=9)$ followed by Australia $(n=2)$, Ireland $(n=2)$, Thailand $(n=2)$, Canada $(n=1)$, Scotland $(n=1)$ and Sri Lanka $(\mathrm{n}=1)$. 


\section{What are Adolescent Men's Attitudes to an Adolescent Pregnancy?}

\section{Pregnancy as a negative event}

Several studies have emphasized that adolescent pregnancy was a major concern for young males (Deslauriers, 2011; Smith et al, 2011; Lanre, 2011; Rink et al, 2012a; Rink et al, 2012b; Wilkes et al, 2012; Lohan et al, 2013; Chili and Maharaj, 2015). Smith et al. (2011) discuss how the men in their study described their anticipated fear, disappointment and shock if faced with a pregnancy. In multiple studies, the consequences of getting a girl pregnant were often conveyed from a life course perspective of personal sacrifices and future restrictions (Buston et al, 2010; Deslauriers, 2011; Wilkes et al, 2012; Lohan et al, 2011; Rajapaksa-Hewageegana, 2014; Chili and Maharaj, 2015). Perceptions of having low personal control over decision-making once pregnancy had occurred were evident in participants' expectations of being "stuck" or "trapped" (Deslauriers, 2011; Smith et al, 2011).

Financial responsibility to rear a child was a core component in the framing of young men's negative attitudes to an adolescent pregnancy, and most especially for young men from working class backgrounds (Buston et al, 2010; Deslauriers, 2011; Jackson et al, 2011; Wilkes et al, 2012; Tanner et al, 2013; Daugherty,2014; Chili \& Maharaj, 2015; Madiba \& Nsiki, 2017). This sense of financial responsibility coupled with a broader sense of patriarchal responsibility was also apparent in studies of university men's attitudes to an unintended adolescent pregnancy (Olmstead et al, 2013; Sharp et al, 2015; Chili \& Maharaj, 2015). Sharp et al (2015) conducted in-depth interviews with ten university students aged 20 - 23 in Australia about their views on the role of young men in the decision-making process regarding pregnancy, views about their rights in unplanned pregnancy and their views on abortion. A prominent theme throughout the interviews was the young men's struggling 
between their own values of wanting to maintain their current way of life and their moral responsibility towards the mother and child. An emerging theme in this study was that these men - who were all in university - felt a responsibility to protect both mother and child and thereby preserving their own identities as upstanding young men. Jackson et al (2011) in their study of low-income fathers in New York, highlight how young men assumed that, as fathers, they would now take on the role of a mature, responsible man, whereas an emerging theme across a range of studies of men in university education, men who were marginally older, from middle class backgrounds, was an expressed desire to be a mature, responsible man before becoming a father (Smith et al, 2011; Olmstead et al, 2013; Sharp et al, 2015).

Despite the pervasiveness of an adolescent pregnancy being perceived as a negative event in the research throughout the studies also young men's remarks reflected an implicit belief that pregnancy prevention was primarily the woman's job (Buston et al, 2010; Sathiparsad, 2010; Jackson et al, 2011; Smith et al, 2011; Weber, 2012; Rossier et al, 2013; Tanner et al, 2013; Daugherty, 2014; Chili \& Maharaj, 2015; Sharp et al, 2015). In a qualitative study of 26 adolescent fathers, Weber (2012) highlights how all but four of the men placed responsibility for the pregnancy directly on the women. Chili and Maharaj (2015) conducted in-depth interviews with seven fathers at the University of Durban, South Africa. The findings from these interviews suggest that the young men did not use contraception to protect against pregnancy as they 'trusted' (pg.32) their partner was using contraception. In a mixed-methods study of 294 male youth from 10 schools in South Africa (Sathiparsad, 2010), survey results indicated that $45.5 \%$ of the sample felt that when a girl has a baby, "it's really her problem". There was one study, which was exceptional in this regard. Zukoski et al. (2011) conducted a study with Latinos residing in the US. Through in-depth interviews with young Latinos $(\mathrm{n}=$ 58 , men $=29$, women $=29$ ) living in rural communities in the Northwest US, this study explored who makes reproductive decisions within heterosexual relationships. Findings from 
this study do not support the view that pregnancy prevention is the girl's job. The majority of men in this study reported that both members decide if they will use something to prevent pregnancy. The researchers revealed that these findings may be indicative of changing cultural beliefs about gender roles within sexual relationships and/or changes that occur in cultural values in the context of immigration to the United States.

\section{Pregnancy as a positive event}

Despite many of the men across these studies viewing an adolescent pregnancy as a negative event, there were some men who viewed adolescent pregnancy as a positive life event, mainly those who had gone on to become fathers (Buston et al, 2010; Deslauriers, 2011; Jackson et al, 2011 Wilkes et al, 2012; Weber, 2012; Frost et al, 2012; Daugherty, 2014; Mann et al, 2015; Wachira et al, 2016). A study of low-income men in the US who had brought about a pregnancy explored how participants viewed continuing pregnancy as an important way to atone for the sexual behaviour that led to pregnancy (Jackson et al, 2011). The majority of men in this study (95\%) had experienced their first pregnancy by the age of 24 , and it is important to recognise that their views are seen retrospectively through the prism of fatherhood. Some of the men viewed their first pregnancies as personally and morally transformative (Buston et al, 2010; Hendricks et al,2010; Jackson et al, 2011; Weber, 2012; Daugherty,2014). In a qualitative study of African American and Puerto Rican men aged 1825 from economically disadvantaged backgrounds in Philadelphia and Hartford, young men believed that having children would make them more mature and some of the men in the study had experienced fatherhood in this way (Daugherty, 2014).

\section{What are Adolescent Men's Attitudes and Decision-Making in Relation to Pregnancy}

\section{Outcomes?}


In terms, first of attitudes to pregnancy outcomes, most studies focus on a single outcome namely abortion. For example, a number of quantitative studies using surveys of attitudes of adolescent men have been conducted (Adaji et al, 2010; Salami \& Ayegboyin, 2015 Altshuler et al, 2015). Altshuler et al. (2015) recruited adolescents in the US between the ages of 13 29 through web-based social media to complete an online survey about sex and pregnancy related decision-making, including abortion. The statement that 'abortion should not be allowed for anyone under any circumstances' was supported by $23 \%$ of males and $19 \%$ of females, and that 'abortion should be allowed and I can imagine some circumstances where I'd have an abortion or I'd want my partner to have an abortion' was supported by $36 \%$ of males and $33 \%$ of females.

By contrast to the generally liberal views in the US, a cross sectional descriptive survey of inschool adolescents in Kenya using random sampling and an inter-generational survey in Nigeria found that most participants expressed conservative views towards abortion and premarital sex (Adaji et al, 2010; Salami \& Ayegboyin, 2015). In Kenya, the majority of male respondents disagreed with allowing abortion for schoolgirls with unwanted pregnancies (86.9\%) (Adaji et al, 2010). Their negative attitude is, however, in conflict with the high rates of abortions among women aged $15-49$ in Kenya, reported in a recent 2015 study (abortion rate of 30 per 100 live births) (Mohamed et al,2015). Salami \& Ayegboyin (2015) conducted an intergenerational study, the study population consisted of 300 respondents from three main groups of different generations; teenagers, both girls who were currently pregnancy and the boys who made them pregnant, teens who had already become parents, and the parents of those teenagers. The author notes that $50 \%$ of the respondents in this study were Christians (National Population Commission, 2006) and about 39\% were Muslims and regards religiosity as being influential in their negative attitude to abortion. 
Findings from a qualitative study with young men from economically disadvantaged backgrounds in the US, concerning pregnancy and fatherhood, (Daugherty, 2014), found the young men to be generally antiabortion and pro-life. The men in this study who were already fathers depicted pregnancy as a foregone conclusion. They expressed the belief that if you impregnate a woman, you should become a father, no one mentioned discussing pregnancy resolution options with their partner.

A qualitative study conducted in Thailand (Sriyaska, 2016), interviewing young couples expecting their first child, reveals how teenage mothers and fathers had similar negative feelings about abortion as it meant going through a physical operation and was against the law. They also expressed concerns about religious beliefs. They believed a Buddhist sin called 'bap', and feared the consequences of this sin. Similarily, Wachira et al (2016) conducted in-depth interviews with 65 Street Connected Children and Youth (SCCY), of which $69.2 \%$ were male, in Eldoret, Kenya. Findings from this study highlight that unwanted pregnancies are commonly terminated or dealt with when the infant is born, e.g. selling of infants, abandon of infants and infanticide. Even though it commonly occurs, abortion is not an acceptable practice among SCCY and is illegal in Kenya. The strong stand against abortion is influenced by the street community's religious beliefs that abortion is sin.

\section{Adolescent Men's Involvement in Pregnancy Decision-Making}

This section deals with studies which examine adolescent men's real and hypothetical involvement in pregnancy decision-making. In a cross-national study using a vignette methodology of a scenario of an unintended pregnancy to a 16-year-old man in a relationship with the female partner, Lohan et al. (2013) report that adolescents in Ireland and Italy were much more likely to choose to continue the pregnancy by comparison with adolescents in Australia. The study confirmed that young men in Australia were relatively more comfortable 
with an adolescent mother's right to choose an abortion. The authors highlight that the social freedom to choose to terminate a pregnancy may be greater in more highly secularized and liberal countries such as Australia, when compared with Ireland and Italy.

Two further qualitative studies using a vignette methodology with adolescent men attending third level education in Australia and the USA serve to further draw out adolescent men's involvement in pregnancy decision-making. In Sharp et al's (2015) Australian study, ten young men were interviewed about their views on their roles in imaginary scenarios and reallife unplanned pregnancy situations ranging from a one-night stand to a two-year relationship. These young men displayed very liberal attitudes to abortion. Some of the young men said that they would not mind if they were not told that the woman decided to have an abortion, as "it would save a lot of stress". However, by contrast, Olmstead et al. (2013) conducted a qualitative content analysis of written responses to hypothetical scenarios from 148 men in higher education in the USA, to questions about pregnancy resolution and marriage in the event of an unplanned pregnancy. The sample was drawn from undergraduate students enrolled in a course on family development at a large South-Eastern University. In this study, $86.5 \%$ of young men in this study said they would expect to raise the child, $10.1 \%$ of young men did not expect to raise the child, with a large number of these men focusing solely on abortion as the way to resolve an unplanned pregnancy and $3.4 \%$ said that they would let their partner decide.

A further qualitative study using a vignette methodology study conducted in Ireland in a scenario of an unintended pregnancy to a 16-year-old man in a relationship, Lohan et al. (2011) report that almost half (46.7 percent) of the adolescent men chose to "keep the baby". Abortion was the second most preferred choice (18.9 percent), closely followed by "leave it up to her "(18.3 percent) with adoption being the least preferred option (16.1\%). This study highlighted how adolescent men's choice to continue the pregnancy in preference to abortion 
was significantly associated with the individual context of their lives, such as their anticipated feelings of regret in relation to abortion (their knowledge and beliefs), perceived positive attitudes of own mother to keeping the baby (their relationships with others) and a feeling that a part of them might want a baby.

Furthermore, some qualitative studies tease out the nuances within the data on men, between the woman's right to control her body and the man's right to be involved (Buston et al, 2010; Deslauriers, 2011; Smith et al, 2011; Olmstead et al, 2013; Tanner et al, 2013; Sharp et al, 2015; Madiba \& Nsiki, 2017). An Australian study (Smith et al, 2011) of men aged 15-25 explored their perceptions of having low control over decision making once the pregnancy outcome had occurred. In this study, the perception that women held greater authority over pregnancy related decisions heightened young males' concern about pregnancy and its occurrence. However, the young men generally accepted that the final decision was "completely up to a woman". A similar result was found in a study among low-income men on the East Coast of the US. Tanner et al (2013) conducted six gender stratified focus groups with 13-19 year olds in Baltimore, Maryland, a city with high rates of teenage pregnancy. There was a consistent message across groups that pregnancy decision-making was the women's responsibility.

Other qualitative studies (Buston et al, 2010; Deslauriers, 2011; Olmstead et al, 2013) with young men clearly suggest that men believe they do not have the right to be involved. Buston (2010) found that some of the incarcerated men in their study did not question their lack of power in the decision-making process. Buston (2010) highlights that pregnancies tended to be seen as the property of the female partner, reflecting both the power of the female partner to claim a pregnancy as her own, and the power of the male partner to be able to leave the consequences of sex largely to the woman. Deslauriers (2011) in a qualitative study with young fathers in Quebec found that the young fathers did not play a role in the decision to 
bring the pregnancy to term. The majority of the young fathers reported that they let their partner make the final decision, however, they did accept responsibility for the pregnancy.

Uniquely in this review period, there was only one study which explored men's actual experiences of the support they offer women when terminating a teenage pregnancy. A small qualitative study in Thailand (Warangkana et al, 2010) explored the type and amount of support men can offer to women who are terminating an unwanted pregnancy. In-depth interviews were conducted with eleven men who had been involved in abortion decisionmaking. These men reported that being involved in the decision and being able to support their partners was a positive experience for them as they were able to support their partner mentally as well as emotionally.

\section{Discussion}

We now summarise findings in relation to:

1. What are adolescent men's attitudes to an adolescent pregnancy?

2. What are adolescent men's attitudes and decision-making in relation to pregnancy outcomes?

One of the most important conclusions of this review is that the findings of studies can often be contradictory. This is because attitudes to unintended pregnancy, contraception and abortion can be contextual and contingent on the dominant or prevailing social norms and roles within a given time, space or social group. In addition, religiosity, age and relationship status are further complicating factors. However, in general, we can conclude that in the vast majority of studies young men perceive actual or potential unintended pregnancies as a life event that will present them with moral and material dilemmas. 
In general, there are some clear identifiable differences in the attitudes to adolescent pregnancy between working class young men in high and low-income countries and middleclass men in university, reflected in their language and perceptions of unintended pregnancy and fatherhood. Young men from working class backgrounds are more likely to view an unintended pregnancy as a positive life event (Buston et al, 2010; Hendricks, 2010; Jackson et al, 2011; Mchunu et al, 2012; Rossier et al, 2013; Wong et al, 2014; Crosby, 2015), an opportunity to transform into a mature, responsible man and father, whereas studies of men in third level education suggest men view an unintended pregnancy as a barrier to becoming a mature and responsible man, as it would affect their ability to plan a career and then plan a baby (Olmstead et al, 2013; Sharp et al, 2015).

What are adolescent men's attitudes and decision-making in relation to pregnancy outcomes?

It is clear from some of the studies in this review that young men, certainly in high-income societies may be exposed to conflicting pressures when faced with an unintended pregnancy. They may feel that they must play a role in discussing or planning for the future with the woman, while at the same time they are influenced by dominant cultural narratives of pregnancy and women's reproductive rights to have control over her body and pregnancy.

On the whole, research based upon large scale surveys suggest that there is broad support for a woman's right to have an abortion among adolescent men. However, this is not a unilateral right. A study conducted by Adaji et al. (2010) on the attitude of Kenyan in-school adolescents on abortion showed that attitudes were largely conservative with a majority of participants disapproving of induced abortion for school girls with unwanted pregnancies. Studies conducted in less economically developed countries such as Africa report more conservative attitudes towards a woman's right to abortion, which the authors have attributed to the significant social and moral influence of religions (Adaji et al, 2010). 
Attitudes to pregnancy outcomes choices, just as attitudes to unintended pregnancy are also influenced by social class differences with more favourable attitudes to abortion prevalent among men in third level education. These attitudes were sharply contrasted in two qualitative studies which explore adolescent men's experiences of pregnancy resolution choices. Young men in third level education discussed how they would not mind if they were not told that a woman was having an abortion as it would "save a lot of stress" (Sharp et al, 2015), whereas, young men in a Young Offenders Institute in Scotland spoke of abortion as being "sick in the head" (Buston, 2010).

Three studies in this review (Buston, 2010; Deslauriers, 2011; Olmstead et al, 2013) draw on adolescent men's actual experiences of an unintended pregnancy and pregnancy outcome choices and these studies showed that adolescent men did not question their lack of power or involvement in the unintended pregnancy outcome decision-making process. These young men did not feel they had, or should have, any right to influence their partner's decision. One unique study (Warangkana et al, 2010) within this review illustrates that where men are afforded the opportunity to support a woman who is terminating an unintended pregnancy they often find it a positive experience. This involvement may provide adolescent men more of a sense of ownership and responsibility due to their proximity to the process.

\section{Limitations of Review}

Reviewing the studies systematically highlights methodological limitations of the evidence. Notably, the studies were overall based on small non-random samples and lacked generalizability. Several studies used a vignette methodology, with researchers discussing how they could not illicit large numbers of young men's responses based on their actual experiences. An integrative review offers a unique perspective of the current literature regarding young men's attitudes in relation to pregnancy and pregnancy outcomes; however, 
there are limitations associated with using different research methods that can contribute to a lack of rigor and bias when developing themes from the data. This review was limited to peer-reviewed articles. Inclusion of grey literature, book chapters and articles not in the English Language might have brought other perspectives.

\section{What This Review Adds}

Out of the 38 studies in this review only 11 studies focused on young men's actual experiences of an unintended pregnancy. Ten of these studies focused on the attitudes and experiences of young fathers, with only one study focusing on young men's actual experiences of abortion (Warangkana,2010). It is clear that there is almost a complete absence of studies conducted that focus specifically on the thoughts and feelings of young men who have experienced an unintended pregnancy and do not go onto become a father. As a result, there are gaps in our understanding concerning the responses of young men whose experience of unintended pregnancy has not been mediated through interaction with, and emotional attachment to, their child. This review also adds new insights over the last review because it has included studies from low-income countries which were excluded from the previous review. These studies add considerable more variation in adolescent men's attitudes to an unintended pregnancy and especially attitudes to abortion and demonstrate even more clearly how the socio-legal context of abortion as well as prevailing norms influence adolescent men's attitudes. From the previous review, we are now seeing studies which have taken more creative routes of recruitment, such as recruiting 'street kids' in Kenya. Nonetheless, there remains a significant bias in research towards safe samples taken from young men in third level education or groups of low-income fathers. 


\section{Recommendations for Future Research}

Despite the considerable progress in research on adolescent men and unintended pregnancy from the previous review to include studies being conducted in low-income countries and research based on the actual experiences of young men and not just hypothetical experiences, there are still gaps in our understanding.

There is a gap in the research on the attitudes and experiences of those young men who do not go onto become a father. Future research should seek to engage with those young men whose partner has an abortion.

Further research should focus on researching couples together. The overwhelming majority of studies conducted on adolescents and unintended pregnancy up to this point have focused on women or men, despite the fact that partners attitudes and intentions have reciprocal influence on one another.

This review has highlighted the breadth of research being conducted in low-income countries, mainly Africa. Future research should include international comparative research studies to draw out how young men's attitudes and decisions making are affected by the wider structural constraints they face in their everyday lives, such as the availability of abortion services, access to counselling services and socio-cultural norms around reproduction in society.

An understanding of young men's experiences of an unintended pregnancy is also a fundamental first step in developing interventions targeted to men to prevent unintended pregnancy. Equally, such knowledge is a necessary first step in offering support and counselling services to adolescent men who experience an unintended pregnancy with a partner. Currently this literature review demonstrates that we do not yet have a significant body of literature to inform practice development. 


\section{Reference List}

Adaji, S.E., Warenius, L.U., Ong'any, A.A., et al. (2010). The attitudes of Kenyan in-school adolescents toward sexual autonomy. African journal of reproductive health, 14(1), 33-41.

Altshuler, A.L., Gerns Storey, H.L. \& Prager, S.W. (2015). Exploring abortion attitudes of US adolescents and young adults using social media. Contraception, 91(3), 226-33.

Boland, R \& Katzive, L. Developments in laws on induced abortion: 1998 - 2007. (2008). International Family Planning Perspectives, 34, 110-120.

Braun, V \& Clarke, V. Using thematic analysis in psychology. (2006) Qualitative Research in Psychology, 3(2), 77 - 101.

Buston, K.M. Experiences of, and attitudes towards, pregnancy and fatherhood amongst incarcerated young male offenders: findings from a qualitative study. (2010). Social science \& medicine, 71(12), 2212-8.

Carter, M., Kraft, J.M., Hock-Long, L. \& Hatfield-Timajchy, K. (2013). Relationship Characteristics and Feelings About Pregnancy Among Black and Puerto Rican Young Adults. Perspectives on Sexual and Reproductive Health, 45(3),148-156. 
Chili, S. \& Maharaj, P. 'Becoming a father': perspectives and experiences of young men in Durban, South Africa. (2015) South African Review of Sociology, 46:3, 28-44.

Crosby, R.A., Graham, C.A., Milhausen, R.R., et al. Desire to father a child and condom use: a study of young black men at risk of sexually transmitted infections. (2015) International Journal of STD \& AIDS ,26(13), 941-4.

Daugherty, J. How Young Men at High Risk of Fathering an Unintended Birth Talk About Their Procreative Identities. (2016). Journal of Family Issues, Vol 37 (13),1817-1842.

Deslauriers, J.M. Becoming a Young Father: A Decision or an "Accident"? (2011). International Journal of Adolescence and Youth, 16:3, 289-308.

Frost, J.J., Lindberg, L.D. \& Finer, L.B. Young Adults' Contraceptive Knowledge, Norms and Attitudes: Associations with Risk Of Unintended Pregnancy. (2012). Perspectives on Sexual and Reproductive Health, 44(2), 107-116.

Glikman, H. Low-Income Young Fathers: contexts, connections and self. (2004). Social Work, 49 (2), 195-206. 
Hendricks, L., Swartz, S. \& Bhana, A. Why Young Men in South Africa Plan to Become Teenage Fathers: Implications for the Development of Masculinities within Contexts of Poverty. (2010). Journal of Psychology in Africa, 20(4), 527-536.

Higgins, J.A., Popkin, R.A. \& Santelli, J.S. Pregnancy Ambivalence and Contraceptive Use Among Young Adults in the United States. (2012). Perspectives on Sexual and Reproductive Health, 44(4), 236-243.

Jackson, E., Karasz, A. \& Gold, M. Family formation in the inner city: low-income men's perception of their role in unplanned conception and pregnancy prevention. (2011). Journal of health care for the poor and underserved, 22(1), 71-82.

Kågesten, A., Bajos, N., Bohet, A., et al. Male experiences of unintended pregnancy: characteristics and prevalence. (2015). Human reproduction (Oxford, England),30(1), 18696.

Lanre, O.O. Secondary School Students' Perception on the Causes and Effects of Unwanted Pregnancy among Adolescents in South West Nigeria. (2011). Research Journal of Medical Sciences, 5(6), 336-339. 
Lewin, A., Mitchell, S., Hodgkinson, S., Gilmore, J. \& Beers, L.S. Pregnancy Intentions among Expectant Adolescent Couples. (2014). North American Society for Paediatric and Adolescent Gynaecology.

Limmer, M. "I Don't Shag Dirty Girls": Marginalised Masculinities and the Use of Partner Selection as a Sexual Health Risk Reduction Strategy in Heterosexual Young Men. (2016). American Journal of Men's Health, Vol 10(2), 128 - 140.

Lohan, M, Cruise, S, O'Halloran, P, et al. Adolescent Men's Attitudes in Relation to Pregnancy and Pregnancy Outcomes: A Systematic Review of the Literature from 1980 2009. (2010). Journal of Adolescent Health, 47 (4), 327-345.

Lohan, M., Cruise, S., O’Halloran, P., et al. Adolescent men's attitudes and decision-making in relation to an unplanned pregnancy. Responses to an interactive video drama. (2011). Social science \& medicine (1982), 72(9), 1507-14.

Lohan, M., Olivari, M.G., Corkindale, C., et al. (2013). Adolescent Men's Pregnancy Resolution Choices in Relation to an Unintended Pregnancy: A Comparative Analysis of Adolescent Men in Three Countries. Journal of Family Issues, 34(8), 1037-1058. 
Madiba, S. \& Nsiki, C. Teen fathers' perceptions and experiences of fatherhood: A qualitative exploration with in-school teen fathers in a rural district in South Africa. (2017). Current Paediatric Research, 21 (3), 5-1-506.

Mann, E.S., Cardona, V. \& Gomez, C.A. Beyond the discourse of reproductive choice: narratives of pregnancy resolution among Latina/o teenage parents. (2015). Culture, Health \& Sexuality, 17:9, 1090-1104.

Marsiglio, W, Lohan, M \& Culley, L. Framing Men's Experiences in the Procreative Realm. (2013). Journal of Family Issues, 34(8), 1011.

Marsiglio, W. “Adolescent Males' Orientation Toward Paternity and Contraception. (1993). Family Planning Perspectives, 25 (1), 22-31.

Mays N, Pope C, Popay J. (2005). Systematically reviewing qualitative and quantitative evidence to inform management and policy-making in the health field. Journal of Health Service Research Policy, 10, 6-20.

McDowell, L. (2002). 'Masculine Discourses and Dissonances: Strutting "Lads", Protest Masculinity, and Domestic Respectability'. Environment and Planning: Society and Space, 20, 97-119. 
Mchunu, G., Peltzer, K., Tutshana, B. \& Seutlwadi, L. (2012). Adolescent pregnancy and associated factors in South African youth. African health sciences, 12(4), 426-34.

Mitchell, E.M., Heumann, S., Araujo, A., et al. (2014). Brazilian adolescents' knowledge and beliefs about abortion methods: a school-based internet inquiry. BMC Women's Health, 14(1), 27.

Mohamed SF, Izugbara C, Moore AM, et al. (2015). The estimated incidence of induced abortion in Kenya: a cross-sectional study. BMC Pregnancy and Childbirth, 15,185.

Nayak, A. (2006). Displaced Masculinities: Chavs, Youth and Class in the Post-industrial city. Sociology 40, Issue 5.

Olmstead, S.B., Koon, J.T., Puhlman, D.J., et al. (2013). College men, unplanned pregnancy, and marriage: what do they expect? Journal of sex research,50(8), 808-19.

Pace, R, Pluye, P, Bartlett, G, et al. Testing the reliability and efficiency of the pilot Mixed Methods Appraisal Tool (MMAT) for systematic mixed studies reviews. (2012). International Journal of Nursing Studies, 49, 47-53.

Pluye, P, Robert, E, Cargo, M, et al. (2011). Proposal: A mixed methods appraisal tool for systematic mixed studies reviews. 
Rajapaksa-Hewageegana, N., Salway, S.M., Piercy, H., et al. (2014). A quantitative exploration of the sociocultural context of teenage pregnancy in Sri Lanka. BMC Pregnancy and Childbirth, 14(1), 394.

Rink, E., FourStar, K., Elk, J.M., et al. (2012). Young Native American men and their intention to use family planning services. American journal of men's health, 6(4), 324-30.

Rink, E., FourStar, K., Elk, J.M., et al. (2012). Pregnancy prevention among American Indian men ages 18 to 24: the role of mental health and intention to use birth control. American Indian and Alaska native mental health research,19(1), 57-75.

Robin, L, Dittus, P, Whitaker, D, et al. (2004). Behavioural interventions to reduce incidence of HIV, STD, and pregnancy among adolescents: a decade in review. The Journal of Adolescent Health; official publication of the Society for Adolescent Medicine, 34 (1), 3-26.

Rocca, C.H., Hubbard, A.E., Johnson-Hanks, J., et al. (2010). Predictive ability and stability of adolescents' pregnancy intentions in a predominantly Latino community. Studies in family planning, 41(3),179-92.

Rossier, C., Sawadogo, N., \& Soubeiga, A. (2013). Premarital Sexuality, Gender Relations and Unplanned Pregnancies in Ouagadougou. Population, 68 (1),97 - 122. 
Salami, K. \& Ayegboyin, M. (2015). Intergenerational Life Courses of Teenage Pregnancy in Ogbomosho South-Western Nigeria, Children and Society,29; 451-461.

Sam Hyun Yoo, Karen Benjamin Guzzo \& Sarah R. Hayford. (2014) Understanding the Complexity of Ambivalence Toward Pregnancy: Does it Predict Inconsistent Use of Contraception? Biodemography and Social Biology, 60:1, 49-66.

Sathiparsad, R. (2014). Young Rural Males in South Africa Speak on Teenage Pregnancy: “It’s Really Her Problem”. Journal of Psychology in Africa, 20:4, 537-546.

Sharp, E., Richter, J. \& Rutherford, A. (2015). “Um... I'm Pregnant.” Young Men's Attitudes Towards Their Role in Abortion Decision-Making. Sexuality Research and Social Policy, 12(2), 155-162.

Sipsma, H., Divney, A.A., Niccolai, L.M., Gordon, D., Magriples, U. \& Kershaw, T.S. (2012). Pregnancy desire among a sample of young couples who are expecting a baby. Perspectives on sexual and reproductive health, 44(4), 244-51.

Sriyasak, A., Almqvist, A.L., Sridawruang, C., Neamsakul,W. \& Haggstrom-Nordin, A. (2016). Struggling with motherhood and coping with fatherhood - A grounded theory study among Thai teenagers. Midwifery, 42,1-9. 
Smith, J.L., Fenwick, J., Skinner, R., et al. (2011). Young males’ perspectives on pregnancy, fatherhood and condom use: Where does responsibility for birth control lie? Sexual \& reproductive healthcare: official journal of the Swedish Association of Midwives, 2(1), 3742

Tanner, A.E., Jelenewicz, S.M., Ma, A, et al. (2013). Ambivalent messages: adolescents' perspectives on pregnancy and birth. The Journal of adolescent health: official publication of the Society for Adolescent Medicine, 53(1),105-11.

United Nations. (2006). The Millennium Development Goals Report.

Promundo and UNFPA. (2016). Strengthening CSO-Government Partnerships to Scale Up Approaches Engaging Men and Boys for Gender Equality and SRHR: A Tool for Action. Washington, D.C.: Promundo-US and New York City, NY: UNFPA.

Wachira, J., Kamanda, A., Embleton, L., Naanyu, V., Ayuku, D., \& Braitstein, P. (2016). 'Pregnancy Has Its Advantages': The Voices of Street Connected Children and Youth in Eldoret, Kenya. PloS one, 11(3), e0150814.

Warangkana, C., Sripichyakan, K., Kantaruksa, K., et al. (2010). Support from Thai Male Partners when an Unwanted Pregnancy is terminated. Pacific Rim International Journal of Nursing Research, 14 (3), 249 - 261. 
Weber, J.B. (2012). Becoming Teen Fathers: Stories of Teen Pregnancy, Responsibility, and Masculinity. Gender and Society, 26 (6), 900-921.

Whittemore, R \& Knafl, K. (2005). The integrative review: updated methodology. Nursing Research, 52(5), 546-53.

Whittemore, R. (2005). Combining evidence in nursing research: methods and implications. Nursing Research, 54(1), 56-62.

Wilkes, L., Mannix, J. \& Jackson, D. (2012). "I am going to be a dad": experiences and expectations of adolescent and young adult expectant fathers. Journal of clinical nursing. 21(1-2),180-8.

Wong, L.P., Atefi, N., Majid, H.A., et al. (2014). Prevalence of pregnancy experiences and contraceptive knowledge among single adults in a low socio-economic suburban community in Kuala Lumpur, Malaysia. BMC public health,14, (Suppl 3).

World Health Organisation. (2011).Evidence for gender responsive actions to prevent and manage adolescent pregnancy. 
World Health Organisation. Health 2020: A European policy framework supporting action across government and society for health and wellbeing.

Zukoski, A.P., Harvey, S.M., Oakley, L., et al. (2011). Exploring power and sexual decision making among young Latinos residing in rural communities. Women's health issues: official publication of the Jacobs Institute of Women's Health, 21(6), 450-7. 